Original Research Paper

\title{
Impact of Ultra Violet Radiation on Polyethylene Packaged Water Exposed at Varying Conditions: Are we Drinking Micro-Plastics?
}

\author{
${ }^{1}$ James Matthew Anayo, ${ }^{2}$ Victor Eshu Okpashi and ${ }^{1}$ Ikechukwu N.E. Onwurah \\ ${ }^{I}$ Department of Biochemistry, Pollution Control and Biotechnology Unit, University of Nigeria, Nsukka, Nigeria \\ ${ }^{2}$ Environmental Toxicology and Molecular Biochemistry Unit, University of Nigeria, Nsukka, Nigeria
}

Article history

Received: 23-10-2017

Revised: $20-11-2017$

Accepted: 26-01-2018

Corresponding Author:

Victor Eshu Okpashi

Environmental Toxicology and

Molecular Biochemistry Unit,

University of Nigeria, Nsukka,

Nigeria

Email: vic2reshu@gmail.com

\begin{abstract}
The public is worried about how their health is impacted by microplastics in sachet water. This awareness has repercussion for water producing factories and public health organization in managing health hazard associated with microplastic ingestion. Many countries in Africa, with concern to Nigeria, the act of packaging water in polyethylene materials by water producing factories has become accustomed. These packaged products are popularly called pure water or sachets water. The packaged materials are made of antioxidants, stabilizers, plasticizers, lubricants, antimicrobials, anti-static and anti-blocking agents. Heat hindrance agents are usually incorporated to improve functionality of polyethylene. It was conceived that the polyethylene material if exposed to sun light radiation over a period of time, its components may leach into the potable water due to photolytic, photo-oxidative and thermo-oxidative reactions caused by fragmentation of the polyethylene material. This research was designed to evaluate the water quality/safety of polyethylene sachet-packaged exposed to direct sunlight at different days. Eighteen polyethylene packaged water were sampled from three different factories Lion water, Galaxy and Ashor water in Nsukka area of Enugu State. They were exposed to sunlight at 31 to $33^{\circ} \mathrm{C}$ for $(24,48,72,96$ and $120 \mathrm{~h})$, respectively. Agilent gas chromatography tandem mass spectroscopy was used to analyze the exposed and unexposed (control) packaged water. Organic compounds such as low molecular weight substituted hydrocarbons, polycyclic aromatic hydrocarbons, trichloromethane, benzene, limonene, xylene, toluene and 2-hexanone were detected in all the exposed samples. These micoplastics which leached into water has been listed by the Agency for Toxic Substances and Disease Registry as potential human carcinogens. The concern now is whether we are drinking micoplastics. The only way out of this perceived health risk is to change the packaging material to prevent ingestion of microplastics in water.
\end{abstract}

Keywords: Microplastics, Polyethylene, Sunlight, Radiation, Water Quality, Exposure

\section{Introdution}

The threat to public health associated with ingestion of water exposed to ultra violet radiation at varying interval is an issue for research and discussion. Human life is surrounded by a wide range of Volatile Organic Compounds (VOCs), including o-xylene causing harmful health effects (Kamal et al., 2015). There have been concerns about the presence of microplastics, which are defined as plastic particles with a diameter less than $5 \mathrm{~mm}$, without lower limit. They are derived from progressive fragmentation of larger debris, or are deliberately made for use in personal care products, medicines and industry (Sandrine et al., 2017). In addition to physical impacts of the plastic particles microplastics are associated with complex mixture of chemicals that may be transfer to humans upon exposure. These chemicals include additives, residual 
monomers and sorbed ambient chemical substances, which are endocrine-disrupting and can adversely, affect human health if ingested (Kole et al., 2017).

Polythene products are identified as low (very low, linear low, medium, linear medium) and high density resins. They are used in the production of boil-in food packages, heat-sealed films, heat-sealed pouches, production of grocery bags, squeezable bottles, cable insulators and production of flexible food packaging, shrink-wrap, stretch film and overwrap film (NOVA, 2012). Polythene and Polyvinylchloride (PVC) is the most frequently used polymer in packaging, an important prerequisite for food packaging (Thorbjörn and Bengt, 2000). During the production of polyethylene, chemical additives are usually incorporated to improve functionality, they include: Antioxidants, stabilizers, plasticizers, lubricants, antimicrobials, anti-static and anti-blocking agents, "slips," or heat resistance agents (Kanishka et al., 2013). More so, polythene used for packaging potable water are often exposed to heat, either by conventional heating or solar radiation. Heating causes the rapid degradation of polythene into different microplastics (Lin et al., 2000; Carsten et al., 2015). Varieties of synthetic polymers absorb ultraviolet radiation and undergo photolytic, photo-oxidative and thermo-oxidative reactions (Scott, 2000). Photooxidative causes the breaking down of polymer chains, radical formation and reduction of molecular weight, leading to leaching of microplastics (Bottino et al., 2004; Emad and Raghad, 2013). These microplastics have health, economics and environmental implications on the final consumers. Traders (hawkers) usually carry these polythene-sachets water about for business, while some marketers abandon the packaged water exposed to sunlight radiation due to lack of space for storage. Microplastics have become prevalent in waters, soil, food webs, indoor and outdoor air. Public concerns about microplastics are mounting as a result of their unknown effects at the micromolecular level and the consequences for human health. There is an expanding knowledge base on microplastics for marine and ecosystems, but the understanding of the human health effects from exposure to microplastics reveals a knowledge gaps. Humans can be exposed to plastic particles via consumption of seafood and terrestrial food products, drinking water and via the air. However, the level of human exposure, chronic toxic effect concentrations and underlying toxicological mechanisms by which microplastics elicit effects are poorly understood to make a full assessment model of the risks to human's exposure. Since sunlight radiation is accompanied with heat, which cause the degradation/fragmentation of polyethylene material and leaching of microplastic into water, investigation was designed to interval.

\section{Materials and Methods}

\section{Sample Collection}

Eighteen sachets water samples; six clusters from three different brands of polyethylene packaged-water were obtained from factories: Lion, Galaxy and Ashor, in Nsukka, Enugu State.

\section{Chemicals/Reagents}

All chemicals were of analytical grade.

\section{Experimental Design}

Fifteen Sachet water, five each from the three brands (Lion, Galaxy, Ashor) were exposed to sun light radiation at 31 to $33^{\circ} \mathrm{C}$ for day $1,2,3,4$ and 5 or $(24,48,72,96$ and $120 \mathrm{~h})$, respectively. At the end of each day, sachet-water samples were collected with sterilized $200 \mathrm{~mL}$ Amber bottle, this was continued to the day 5. Three samples were used as control (unexposed). The samples were analyzed with gas chromatography tandem mass spectroscopy.

\section{Intervals of Exposed Samples:}

- Sample a-exposure on day $1(24 \mathrm{~h})$ at 31 to $33^{\circ} \mathrm{C}$

- Sample b-exposure on day $2(48 \mathrm{~h})$ at 31 to $33^{\circ} \mathrm{C}$

- Sample c-exposure on day $3(72 \mathrm{~h})$ at 31 to $33^{\circ} \mathrm{C}$

- Sample d-exposure on day $4(96 \mathrm{~h})$ at 31 to $33^{\circ} \mathrm{C}$

- Sample e-exposure on day $5(120 \mathrm{~h})$ at 31 to $33^{\circ} \mathrm{C}$

- Sample f-control (sachet water sample unexposed to sunlight) 2 to $15^{\circ} \mathrm{C}$

\section{Preparation of Samples for GC-MS Analysis}

Water samples were transferred into glass containers with Teflon lined septa. The sample container was filled just to overflow in order to void air bubble passing through the bottle. The sample bottles were sealed with screw caps to prevent air bubbles entrapment. Gas chromatography-Mass Spectroscopy with purge and trap technique was performed using Agilent Technologies $7890 \mathrm{~A}$ and $5975 \mathrm{~N}$ mass selective detector procedure. The samples were placed in a sealed vessel and arranged in auto-sampler. The transfer line was connected directly into the GC injector by a needle. Injector mode was used in the split-split less injector. The samples were purged with inert gas concentrator, causing Volatile Organic Compounds (VOCs) to sweep out of the samples. The VOCs were retained in an analytical trap to allow purge gases to pass through the vent. The VOCs were then desorbed by heating the trap injected into the GC by back flushing the trap with carrier gas. Microplastics were identified by comparing measured retention data with structure-retention correlations, mass spectra and interpreted via matching the results with library spectra. 


\section{Condition of $G C-M S$}

The following were the condition of the GC-MS with Purge and Trap technique:

Injection: purge and trap split (split ratio 35:1), Liner: $1 \mathrm{~mm}$ Split (cat.\# 20972-214.1)

Inj. Temp.: $200^{\circ} \mathrm{C}$, Purge and Trap, instrument: OI 4660 Eclipse Purge and Trap, Trap Type: \#10 (Tenax®/silica gel/carbon molecular sieve), Purge: $11 \mathrm{~min}$, flow 40 $\mathrm{mL} / \mathrm{min}$, Desorb Preheat Temp.: $185^{\circ} \mathrm{C}$, Desorb: $0.5 \mathrm{~min} @$ $190^{\circ} \mathrm{C}$, flow $35 \mathrm{~mL} / \mathrm{min}$, Bake: $8 \mathrm{~min} @ 210^{\circ} \mathrm{C}$, Interface Connection: injection port, Transfer Line Temp.: $150^{\circ} \mathrm{C}$, Oven Temp.: $40^{\circ} \mathrm{C}$ (hold $4 \mathrm{~min}$ ) to $90^{\circ} \mathrm{C}$ at $16^{\circ} \mathrm{C} / \mathrm{min}$ to $220^{\circ} \mathrm{C}$ at $32^{\circ} \mathrm{C} / \mathrm{min}$ (hold $5 \mathrm{~min}$ ), Carrier Gas: He, constant flow, Linear velocity: $34 \mathrm{~cm} / \mathrm{sec} @ 40^{\circ} \mathrm{C}$, Detector: MS, Mode: Scan, Transfer Line Temp.: $150^{\circ} \mathrm{C}$, Ionization Mode: EI, Scan Range: 35-300 amu, Column: Rtx ${ }^{\circledR}-\mathrm{VMS}, 30 \mathrm{~m}, 0.25 \mathrm{~mm}$ ID, $1.40 \mu \mathrm{m}$ (cat.\# 19915), 502.2 Calibration Mix \#1 (gases), $2000 \mu \mathrm{g} / \mathrm{mL}$ in methanol (cat.\# 30042), Diluents: $25 \mathrm{~mL}$ water.

\section{Results}

The chromatograms and Tables bear's the concentation and percentage composition for all compounds detected, while chromatograph can be found at the appendicies. The analysis was ran under the same conditions to compare results of varied exposure days.

\section{Discussion}

The polyethylene packaged water exposed to sunlight radiation at varying temperature and duration, followed similar trend. The compounds with higher molecular with gave the highest concentration exemplified in the Tables and Chromatograms. For instance, Cyclotetradecane; 9Octadecene, (E)-; 2-Tetradecene, (E)- had 12.532 ppm, followed by $8.156 \mathrm{ppm}$ - Cyclotetrasiloxane, octamethyland lastly-ethylene oxide $1.243 \mathrm{ppm}$ Table 1. Low molecular weight, typically monomers and residual solvents (e.g., ethylene oxide, methylene chloride, acetic acid and methane) were quick to elude. According to COWI (2013), monomers such as formaldehyde, vinyl chloride, ethylene oxide and butadiene are gases with tendency to migrate rapidly at ambient temperatures. In addition, solubility also determine the rate of migration of substances i.e., the higher the solubility of the plastic polymer, the less the rate of migration of such substance (COWI, 2013). As temperature increases, the leaching of monomers, oligomers and other compounds increases (Kanishka et al., 2013). As the duration of exposure increases, the internal and/or external chromophoric groups in the packaging material absorb sunlight radiation and produce low molecular weight radicals $(\mathrm{R})$ or polymeric macro radicals $(\mathrm{P})$ through photo-oxidation (Cheshire et al., 2009). Octamethyl, (E)-9-Octadecene and (E)-2-Tetredecene radicals were produced after day 1 exposure to sunlight, Table 1 and 2 (the onset of fragmentation and degredation). This reaction is also referred to as Norrish initiation or photo-degradation reaction (Yousif, 2012). The radicals produced in photoinitiation step proceeds to propagation step, where they undergo reaction with polythene polymer in a chain process to produce low molecular radicals, hydroxyl and polymer alkyl/peroxy/alkyloxy radicals (Soják et al., 2006). This give rise to the production of more radicals on day 3 to 5 exposed samples Table 3 to 5 .

Zhang and Song (2005) reported that VOCs containing xylene and formaldehyde may also impair the memory and hearing ability in mice. Also, female workers' in the jewel processing factories are prone to DNA damage in the peripheral blood cells exposed to xylene, benzene and toluene simultaneously (Wei et al., 2009). According to Huang et al. (2004), fatigue, conjunctivitis, memory deterioration and hand degreasing is common with individual exposed to microplastics. Low level exposure to mixed - xylene containing benzene and toluene may lead coryza, catamenai disruption, dermatitis and pharyngitis. These mixtures are harmful to reproductive system, nerve system mucous membrane and cuffs (Wang et al., 2004). Carbon dioxide - $1.516 \mathrm{ppm}$ and $78.66 \%$ composition can reason injury to human health.

Table 1: Compounds detected on day 1 exposure to sunlight radiation

\begin{tabular}{lccl}
\hline Peak & Concentration ppm & \% Composition & Compounds Identified \\
\hline 1 & 1.243 & 68.66 & Ethylene oxide; Ethyne, fluoro- \\
2 & 1.523 & 16.82 & Methylene Chloride \\
3 & $6.998^{*}$ & 5.21 & Acetic acid \\
4 & $8.156^{*}$ & 5.63 & Cyclotetrasiloxane, octamethyl- \\
5 & $12.532^{*}$ & 3.68 & Cyclotetradecane; 9-Octadecene, (E)-; 2-Tetradecene, (E)- \\
\hline
\end{tabular}

The microplastics marked with asterisks $(*)$ have concentration above permissible limit

Chromatogram is found in appendix 1

Table 2: Compounds detected on day 2 exposure to sunlight radiation

\begin{tabular}{llll}
\hline Peak & Concentration ppm & \% Composition & Compounds identified \\
\hline 1 & 1.516 & 78.66 & Carbon dioxide; Ethylene oxide \\
2 & 1.873 & 13.59 & Methylene Chloride \\
3 & $6.419^{*}$ & 7.75 & Acetic acid \\
\hline
\end{tabular}

The microplastics marked with asterisks $(*)$ have concentration above permissible limit

Chromatogram is found in appendix 2 
Table 3: Compounds detected on day 3 exposure to sunlight radiation

\begin{tabular}{llcl}
\hline & Concentration & & \\
Peak & $\mathrm{ppm}$ & \% Composition & Compounds identified \\
\hline 1 & 1.506 & 22.23 & Carbon dioxide; Ethylene oxide \\
2 & 1.629 & 6.74 & Formic acid hydrazide; Hydrazine, 1, 1-dimethyl- \\
3 & 1.818 & 6.04 & Methane, dimethoxy- \\
4 & 2.288 & 1.41 & Trichloromethane; Methane, bromodichloro-; Trichloromethane \\
5 & 4.548 & 19.70 & Toluene \\
6 & $6.265^{*}$ & 0.96 & Acetic acid \\
7 & $6.648^{*}$ & 2.56 & Benzene, 1,3-dimethyl-; o-Xylene \\
8 & $7.062^{*}$ & 0.70 & o-Xylene; Benzene, 1,3-dimethyl- \\
9 & $7.734^{*}$ & 1.21 & 1R-.alpha.-Pinene; Bicyclo[3.1.1]hept-2-ene, 2,6,6-tetramethyl-, \\
& & & (.+--.)-; .alpha.-Pinene \\
10 & $8.162^{*}$ & 0.89 & Benzene, 1-ethyl-2-methyl- \\
11 & $8.561^{*}$ & 3.39 & 1-Decene; Cyclopropane, nonyl- \\
12 & $8.615^{*}$ & 2.54 & Benzene, 1,2,3-trimthyl-, 1,2,4-trimethyl- \\
13 & $8.844^{*}$ & 3.11 & 3-Carene \\
14 & $9.033^{*}$ & 1.02 & Benzene, 1-methyl-4-(1-methylethyl)-, 1-methyl-2-(1-methylethyl)- \\
15 & $9.088^{*}$ & 1.10 & Limonene; D-Limonene \\
16 & $10.924^{*}$ & 14.30 & 1-Dodecene; 2-Dodecene, (Z)-; 1-Undecanol \\
17 & $11.004^{*}$ & 0.76 & Dodecane; Hexadecane; Undecane \\
18 & $11.062^{*}$ & 1.73 & 6-Dodecene, (Z)-; 5-Dodecene, (Z)-; 6-Dodecene, (E)- \\
19 & $11.162^{*}$ & 1.28 & 2-Dodecene, (Z)-; 3-Dodecene, (Z)-; 2-Dodecene, (E)- \\
20 & $12.078^{*}$ & 0.71 & Naphthalene, 2-methyl-, 1-methyl- \\
21 & $12.843^{*}$ & 7.62 & Cyclopropane, nonyl-; 1-Tetradecene; 2-Tetradecene, (E)- \\
\hline
\end{tabular}

The microplastics marked with asterisks (*) have concentration above permissible limit

Chromatogram is found in appendix 3

Table 4: Compounds detected on day 4 exposure to sunlight radiation

\begin{tabular}{llll}
\hline & Concentration & $\%$ & \\
Peak & ppm & Composition & Compounds identified \\
\hline 1 & 1.493 & 22.87 & Carbon dioxide; Ethylene oxide \\
2 & 1.616 & 7.77 & Formic acid hydrazide; Ethyne, chloro-; Thiirane \\
3 & 1.792 & 6.32 & Methane, dimethoxy- \\
4 & 2.259 & 1.15 & Trichloromethane; Ethane, 1,2,2-trichloro-, 1, 1-difluoro- \\
5 & 4.503 & 5 & Toluene; 1,3,5-Cycloheptatriene \\
6 & $6.477^{*}$ & 0.7 & Ethylbenzene \\
7 & $6.625^{*}$ & 3.21 & o-Xylene; p-Xylene \\
8 & $7.043^{*}$ & 0.83 & Benzene, 1,3-dimethyl-; o-Xylene; p-Xylene \\
9 & $7.725^{*}$ & 1.36 & alpha.-Pinene; 1R-.alpha.-Pinene; Bicyclo[3.1.1]hept-2-ene \\
10 & $8.152^{*}$ & 1.01 & Benzene, 1-ethyl-4-methyl-, 1-ethyl-3-methyl-, 1-ethyl-2- \\
11 & $8.557^{*}$ & 4.12 & 1-Decene \\
12 & $8.612^{*}$ & 3.22 & Benzene, 1,2,3-trimthyl-, 1,2,4-trimethyl- \\
13 & $8.75^{*}$ & 0.69 & cis-3-Carene; 4-Decene; trans-4-Decene \\
14 & $8.84^{*}$ & 3.9 & 3-Carene; 1S-.alpha.-Pinene \\
15 & $9.03^{*}$ & 1.19 & Benzene, 1-methyl-4-(1-methylethyl)-, 1-methyl-3-(1-methylethyl)-, \\
& & & 1-methyl-2-(1-methylethyl)- \\
16 & $9.085^{*}$ & 1.29 & Limonene; D-Limonene \\
17 & $9.918^{*}$ & 0.83 & Undecane \\
18 & $10.927^{*}$ & 19.32 & 1-Dodecene; 5-Dodecene, (E)-; 2-Dodecene, (Z)- \\
19 & $11.008^{*}$ & 0.97 & Dodecane; -octadecanesulphoyl chloride \\
20 & $11.062^{*}$ & 2.22 & 5-Dodecene, (Z)-; 3-Dodecene, (E)-; 6-Dodecene, (Z)- \\
21 & $11.162^{*}$ & 1.64 & 2-Dodecene, (Z)-; 2-Dodecene, (E)- \\
22 & $12.843^{*}$ & 9.66 & 1-Tetradecene; 2-Tetradecene, (E)-; 1-Dodecene \\
23 & $12.956^{*}$ & 0.73 & 5-Tetradecene, (E)-; 3-Tetradecene, (E)- \\
\hline
\end{tabular}

The microplastics marked with asterisks $\left(^{*}\right)$ have concentration above permissible limit

Chromatogram is found in appendix 4 
Table 5: Compounds detected on day 5 exposure to sunlight radiation

\begin{tabular}{llcl}
\hline Peak & Concentration ppm & \% Composition & Compounds identified \\
\hline 1 & 1.510 & 29.23 & Carbon dioxide; Ethylene oxide \\
2 & 1.623 & 6.43 & Formic acid hydrazide; Hydrazine, 1,1-dimethyl- \\
3 & 1.822 & 9.73 & Methane, dimethoxy- \\
4 & 2.291 & 2.23 & Trichloromethane \\
5 & 4.539 & 19.80 & Toluene \\
6 & $6.632^{*}$ & 2.32 & Benzene, 1,3-dimethyl-; p-Xylene \\
7 & $6.757^{*}$ & 0.90 & Acetic acid, anhydride with formic acid \\
8 & $8.554^{*}$ & 2.24 & Cyclodecane; 1-Decene; Cyclopropane, 1-methyl-2-octyl- \\
9 & $8.609^{*}$ & 2.22 & Benzene, 1,2,3-trimthyl-, 1,2,4-trimethyl-, 1,3,5-trimethyl- \\
10 & $8.841^{*}$ & 2.04 & 1R-.alpha.-Pinene; 3-carene \\
11 & $10.921^{*}$ & 12.97 & 1-Dodecene; 2-Dodecene, (Z)-; 1-Undecanol \\
12 & $11.062^{*}$ & 1.41 & 3-Dodecene, (E)-; 5-Dodecene, (E)- \\
13 & $11.162^{*}$ & 0.99 & 2-Dodecene, (Z)-; Cyclopropane, 1-butyl-2-pentyl-, cis-; 6-Dodecene, (Z)- \\
14 & $12.844^{*}$ & 7.50 & 4-Tetradecene, (E)-; 2-Tetradecene, (E)-; 1-Tetradecene \\
\hline
\end{tabular}

Chromatogram is found in appendix 5

The microplastics marked with asterisks $(*)$ have concentration above permissible limit

The control samples have no peaks (F). No microplastics in the control samples.

Furthermore, as the durations of exposure increases to day 3, 4 and 5, more microplastics progressively leached into the water appendix 3 and Table 3. Naphthalene - $12.078 \mathrm{ppm}(0.71 \%)$ composition and tetradecene $-12.843 \mathrm{ppm}$ had the highest concentration, but varies in composition and concentration with oxylene, dodecene and limonene. In Table three and appendix three, it was observed that many different microplstics leached into the packaged water. Therefore, it was concluded that upon exposure of Sachet water, the day three leaching was most significant. Thus, day four and day 5 the microplastic level begins to decrease due to volitalization and evaporation, while day 1 and day 2 was assum to be the onset of fragmentation/degradation.

Photo-degradation/fragmentation process causes the leaching of unreacted monomers, oligomers and additives incorporated in the plastic polymer (Carsten et al., 2015). COWI (2013), states that hydrazine, methylene Chloride, formamide, dimethylformamide, limonene and Dlimonene, naphthalene, 2-methylnaphthalene, ethylene oxide, cyclopropane, ethane, trichloromethane, ethylbenzene. Ethylene oxide, ethane, cyclopropane, trichloromethane are volatiles, while ethylbenzene, limonene and D-limonene are monomers. Guo et al. (2010) reported that hydrazine is an intermediate in production of blowing agents in thermoplastics, flame retardants for nylon and smoke suppressant additives for polyurethane foam; formamide and dimethylformamide are used as solvent and plasticizer in consumer products. Also, naphthalene, 2-methylnaphthalene and 1methylnaphthalene are impurity in plasticisers (BFR, 2015). The leaching of these additives under different study conditions was reported by (Biedermann et al., 2008). Some of these additives are harmful to humans, even at the worst nadir value (Fasano et al., 2012). Many of this compounds detected are among the Priority List of hazardous substances by Agency for Toxic Substances and Disease Registry (ATSDR, 2015). These includes: trichloromethane (Chloroform), naphthalene, benzene, xylene, toluene, 2-hexanone, methane, Methylene chloride, hydrazine, 1, 2-dichloroethane, Acetone, formaladehyde, 2butanone, 2-Butene, Silanes, Ethylene oxide, hexanal, propanal, decane, dodecane, cycloheptatriene, cyclohexadecane, undecan. Naphthalene has been listed by the US Environmental Protection Agency as priority environmental pollutants (US EPA, 2014). Naphthalene and hydrazine have been confirmed by U.S. Environmental Protection Agency (EPA) as a group C and group 2B, possible human carcinogen (US EPA, 2016).

Clausen et al. (2001 - quoted from CICAD 1998) reported that $72 \%$ of $d$-limonene metabolites were excreted in male rabbit urine $72 \mathrm{~h}$ after oral administration, while $7 \%$ was found in the faeces. In humans, about $25-30 \%$ of an oral dose of $d$-limonene was found in urine as $d$-limonene-8,9-diol (M-II) and its glucuronide (M-VI); about $7-11 \%$ was eliminated as perillic acid (M-III) and its metabolites (Dietrich and Swenberg (1991a) - quoted from CICAD 1998). DLimonene-8, 9-diol is most probably formed via $d$ limonene-8,9-epoxide (Dietrich and Swenberg, 1991b; EMEA 2002-both quoted from CICAD 1998). Cyclodecane, dodecene, methane, hydrazide and hydrazine were detected in day 5 exposed samples at different composition and concentration. Ethylene oxide is a known toxicant, which is listed among the 30 chemicals of concern due to it implication on reproductive and developmental consequences. IARC, (1994) concluded that ethylene oxide is carcinogenic to humans. US EPA has classified ethylene oxide as a Group B1, probable human carcinogen. Therefore this research has set up a lead way to avoiding the use of exposed polyethylene packaged water for consumption at temperature range of 31 to $33^{\circ} \mathrm{C}$, as its future health effect may be detrimental to the public. Finally fiugure 1 to 5 are annexed as appendices. There are chromatograms with retention time and $\%$ area data compound identified. Each chromatogram was ran under the same conditions to allow for comparison between results of different days of exposure. 
They beging from appendix or figure 1,2, 3, 4 and 5, respectively. Representing chromatogram for sample $a, b$, $\mathrm{c}, \mathrm{d}$ and e, sequentially.

\section{Conclusion}

The presence of microplastics in water justified the knowledge gap that leaching do occur when polythenesachet water are exposed to sunlight radiation. Indeed, the public is consuming microplastics. Based on findings some of these microplastics are among the priority list of hazardous substances as potential endocrine disruptor and repro-toxic substances.

\section{Acknowledgement}

We are grateful to Mr. Paul Nwachukwu of the International Energy Center Port Harcourt for his knowledge and time of runing the GC/MS analysis.

\section{Authors Contributions}

Okpashi Victor Eshu: Design the work, write the manuscript and supervised the work.

James Matthew Anayo: Did the field work and laboratory analysis.

Ikechukwu N.E. Onwurah: The lead research/Supervisor.

\section{Ethics}

The authors hereby declare no conflict of interest regarding the publication of this article.

\section{References}

ATSDR, 2015. Priority list of hazardous substances. ATSDR, Division of Toxicology and Human Health Sciences, Webpage: Error! Hyperlink reference not valid.

BFR, 2015. Microplastic particles in food. BFR Opinion No. 013/2015, German Federal Institute for Risk Assessment.

Biedermann, M., K. Fiselier and K. Grob, 2008. Testing migration from the PVC gaskets in metal closures into oily foods. Trends Food Sci. Technol., 19: 145-55. DOI: 10.1016/j.tifs.2007.08.008

Bottino, F.A., A.R. Cinquegrani, G. Di Pasquale, L. Leonardi and A. Pollicino, 2004. Chemical modifications, mechanical properties and surface photo-oxidation of films of Polystyrene (PS). Polymer Test., 23: 405-411.

DOI: $10.1016 /$ j.polymertesting.2003.10.001

Carsten, L., F.H. Steffen, M. Kerstin, N. Fredrik and I.B.H. Nanna et al., 2015. Microplastics: Occurrence, Effects and Sources of Releases to the Environment in Denmark. 1st Edn., The Danish Environmental Protection Agency, Denmark, Copenhagen K, pp: 205.
Cheshire, A., E. Adler, J. Barbière, Y. Cohen and S. Evans et al., 2009. UNEP/IOC guidelines on survey and monitoring of marine litter. UNEP Regional Seas Reports and Studies, No. 186; IOC Technical Series No 83.

CICAD, 1998. Limonene. Concise International Chemical Assessment Document No. 5. Inter-Organization Programme for the Sound Management of Chemicals, World Health Organization, Geneva.

Clausen, P.A., C.K. Wilkins, P Wolkoff and G.D. Nielsen, 2001. Chemical and biological evaluation of a reaction mixture of $R-(+)$-limonene/ozone: Formation of strong airway irritants. Environ. Int., 26: 511-522. DOI: $10.1016 / \mathrm{S} 0160-4120(01) 00035-6$

COWI, 2013. Hazardous substances in plastic materials. A report prepared by Erik Hansen, COWI-Denmark, Nils H. Nilsson, Danish Technological Institute, Delilah Lithner, COWI-Sweden and Carsten Lassen COWI Denmark. COWI and Danish Technological Institute Publication.

Dietrich, D.R. and J.A. Swenberg, 1991a. NCI-Black-Reiter (NBR) male rats fail to develop renal disease following exposure to agents that induce $\alpha$-2u-globulin $(\alpha 2 \mathrm{u})$ nephropathy. Fundam. Applied Toxicol., 16: 719-762. DOI: 10.1016/0272-0590(91)90161-V

Dietrich, D.R. and J.A. Swenberg, 1991b. The presence of $\alpha 2 \mathrm{u}$-globulin is necessary for $d$-limonene promotion of male rat kidney tumors. Cancer Res., 51: 3512-3521.

Emad, Y. and H. Raghad, 2013. Photodegradation and photostabilization of polymers, especially polystyrene: Review. Springerplus, 2: 398-398. DOI: $10.1186 / 2193-1801-2-398$

EMEA, 2002. Terebinthinae aetheroleum rectifi-catumsummary report. The European Agence for the Evaluation of Medicinal Products, Commit-tee for Veterinary Medicinal Products. www.emea.eu.int

Fasano, E., F. Bobo-Blay, T. Cirillo, P. Montuori and S. Lacorte, 2012. Migration of phthalates, alkylphenols, bisphenol $\mathrm{A}$ and di(2-ethylhexyl)adipate from food packaging. Food Control, 27: 132-138. DOI: 10.1016/j.foodcont.2012.03.005

Guo, Z., S. Wang, D. Wei, M. Wang and H. Zhang et al., 2010. Development and application of a method for analysis of phthalates in ham sausages by solidphase extraction and gas chromatography-mass spectrometry. Meat Sci., 84: 484-490. DOI: $10.1016 /$ j.meatsci.2009.10.002

Huang, L.J., S.B. Fang and C.D. Chen, 2004. Effect of benzene, toluene, xylene occupational exposure on DNA damage of peripheral blood cells in female jewel processing workers. Mod. Prev. Med., 13: 006-006.

IARC, 1994. Some Industrial chemicals: Ethylene oxide. Lyon, International Agency for Research on Cancer, (IARC Monographs on the Evaluation of Carcinogenic Risks to Humans). 
Kamal, N., B. Haji, M. Faheem and A. Mohammad, 2015. A review of environmental and occupational exposure to xylene and its health concerns. EXCLI J., 14: 1167-1186. DOI: 10.17179/excli2015-623

Kanishka, B., S. Shyam, J.T. Sablani and R. Barbara, 2013. Migration of chemical compounds from packaging polymers during microwave, conventional heat treatment and storage. Comprehensive Rev. Food Sci. Food Safety, 12: 523-545.

DOI: $10.1111 / 1541-4337.12028$

Wear and tear of tyres: A stealthy source of microplastics in the environment. Int. J. Environ. Res. Public Health, 14: 1265-1265. DOI: 10.3390/ijerph14101265

Lin, J.F., C.F. Ho and S.K. Huang, 2000. Studies on curing kinetics and total thermal degradation of the modified epoxy copolymer with penta-coordinated phosphate as a tribranched junction. J. Applied Polymer Sci., 77: 719-732. DOI: $10.1002 /(\mathrm{SICI}) 1097-$ 4628(20000725)77:4<719::AID-APP2>3.0.CO;2-7

NOVA, 2012. Material Safety Data Sheets (MSDS): Product risk profile. Polyethylene. Nova Chemicals Inc. 1555 Coraopolis Heights Road, Moon Township, PA USA. www.novachemicals.com.

Sandrine, S., E.H. Philipp and B.H. Patricia, 2017. Biodegradable and petroleum-based microplastics do not differ in their ingestion and excretion but in their biological effects in a freshwater invertebrate gammarus fossarum. Int. J. Environ. Res. Public Health, 14: 774-774. DOI: 10.3390/ijerph14070774
Scott, G., 2000. 'Green' polymers. Polymer Degradat. Stabilizat., 68: 1-7. DOI: 10.1016/S0141-3910(99)00182-2

Soják, L., R. Kubinec, H. Jurdáková, E. Hájeková and M. Bajus, 2006. Review GC-MS of polyethylene and polypropylene thermal cracking products. Petroleum Coal, 48: 1-14

Thorbjörn, A. and W. Bengt, 2000. Degradation of LDPE LLDPE and HDPE in film extrusion. J. Applied Polymer Sci. Technol., 86: 1580-1586.

US EPA, 2014. PAHs. Webpage:

US EPA, 2016. Hydrazine. Webpage:

Wang, H.Q., C.Y. Lei, D.Y. Huang and H. Wang, 2004. Adverse effect of low level exposure to mixture of benzene, toluene and xylene. Occup. Health Emerg. Rescue, 2: 002-002.

Wei, D.Y., M.L. Wang, Z.Y. Guo, S. Wang and H.L. $\mathrm{Li}$ et al., 2009. GC/MS method for the determination of adipate plasticizers in ham sausage and its application to kinetic and penetration studies. J. Food Sci., 74: 392-398. DOI: $10.1111 /$ j.1750-3841.2009.01183.X

Yousif, E., 2012. Photostabilization of Thermoplastic Polymers. 1st Edn., Lambert Academic Publishing, Germany, pp: 398.

Zhang, H.Z. and W.M. Song, 2005. Neurotoxic effect of exposure of mice to volatile organic compounds. J. Labour. Med., 2: 006-006.

\section{Appendices}

\section{Appendix 1}

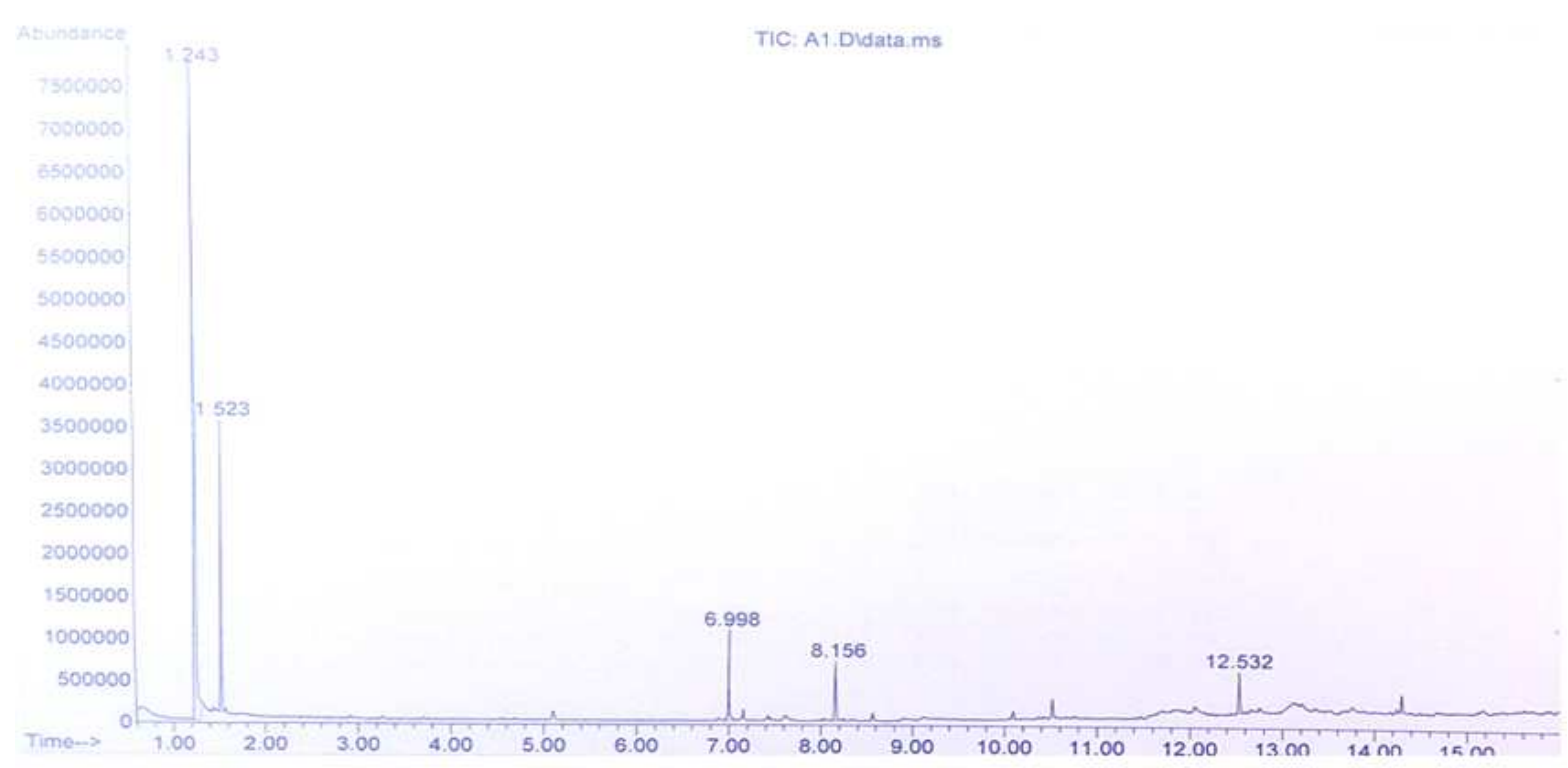

Fig. 1: Chromatogram for sample a, results is presented in Table 1 


\section{Appendix 2}

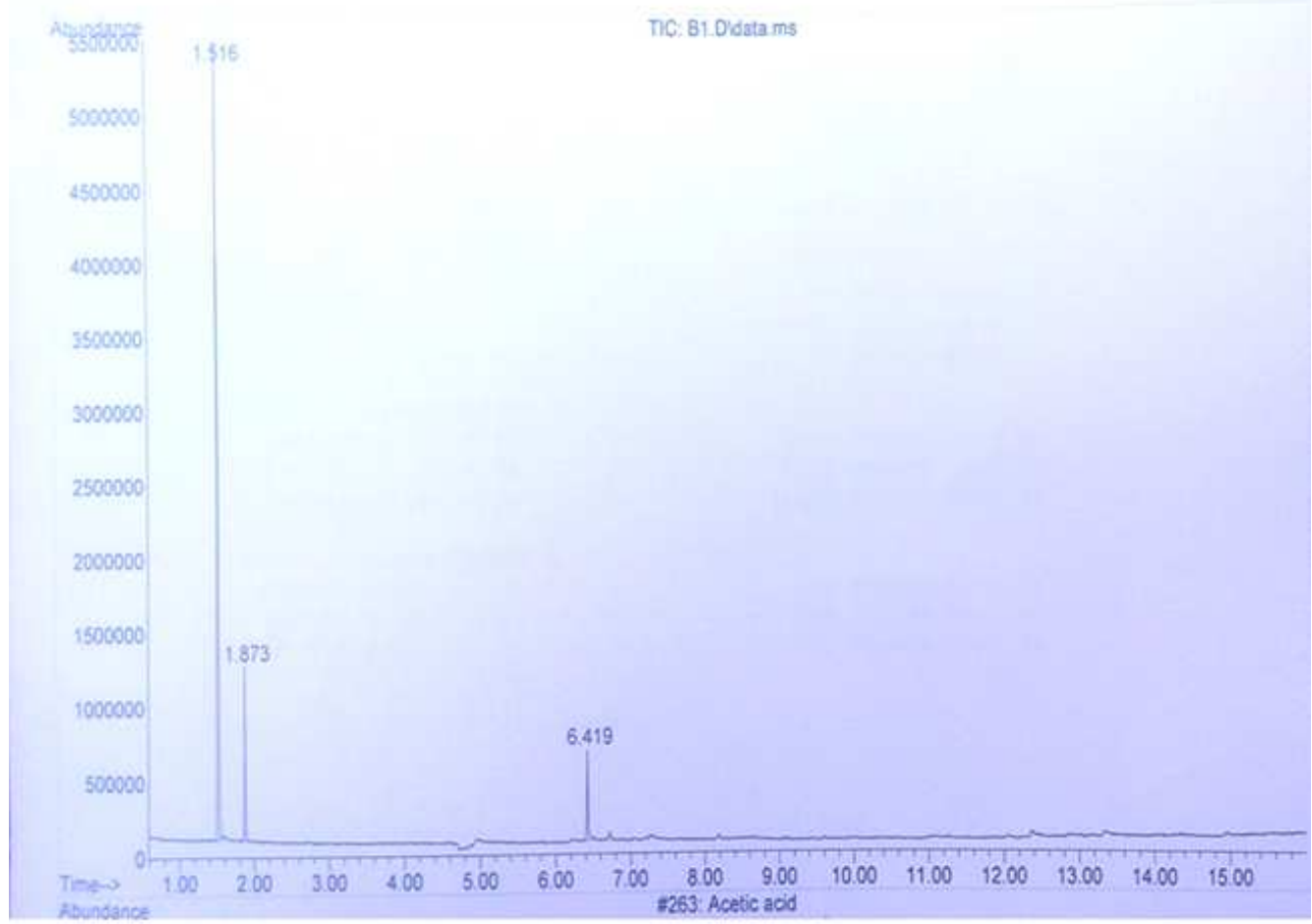

Fig. 2: Chromatogram for sample b, results is presented in Table 2

\section{Appendix 3}

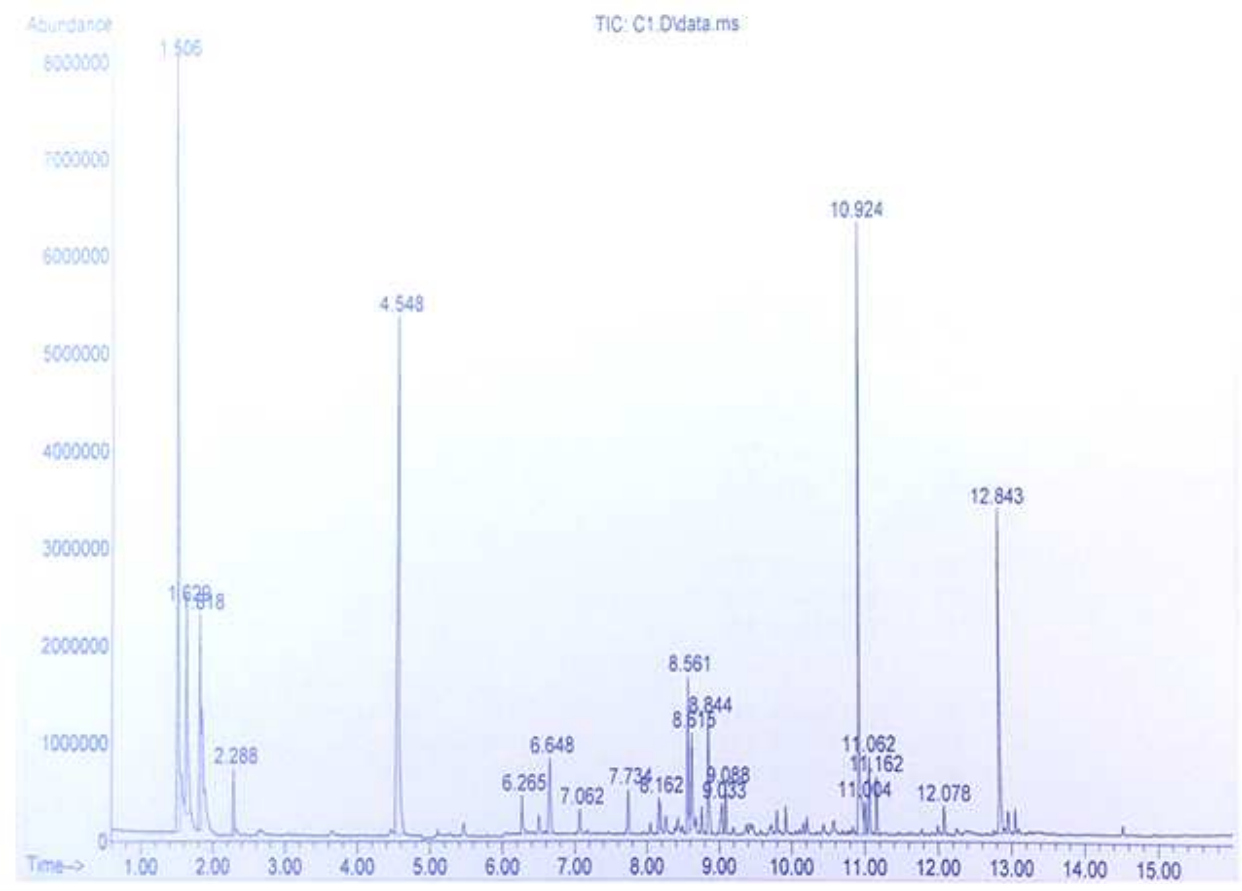

Fig. 3: Chromatogram for sample c, results is presented in Table 3 


\section{Appendix 4}

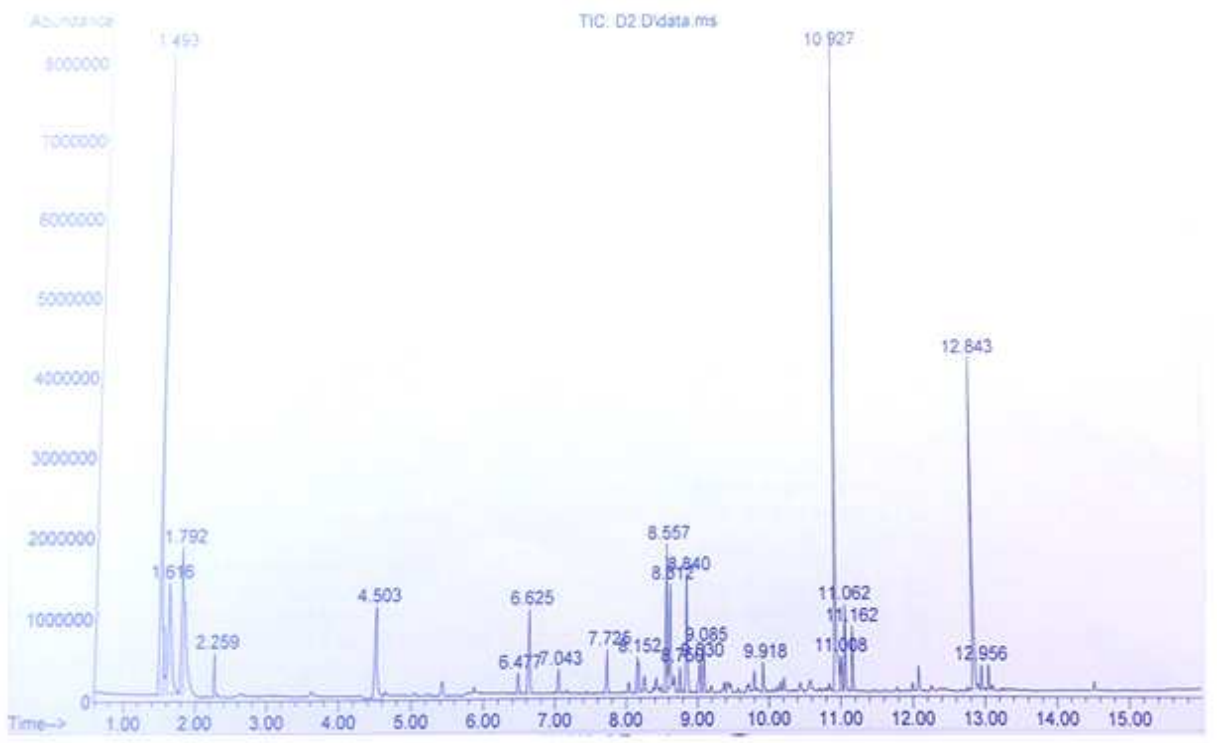

Fig. 4: Chromatogram for sample d, results is presented in Table 4

\section{Appendix 5}

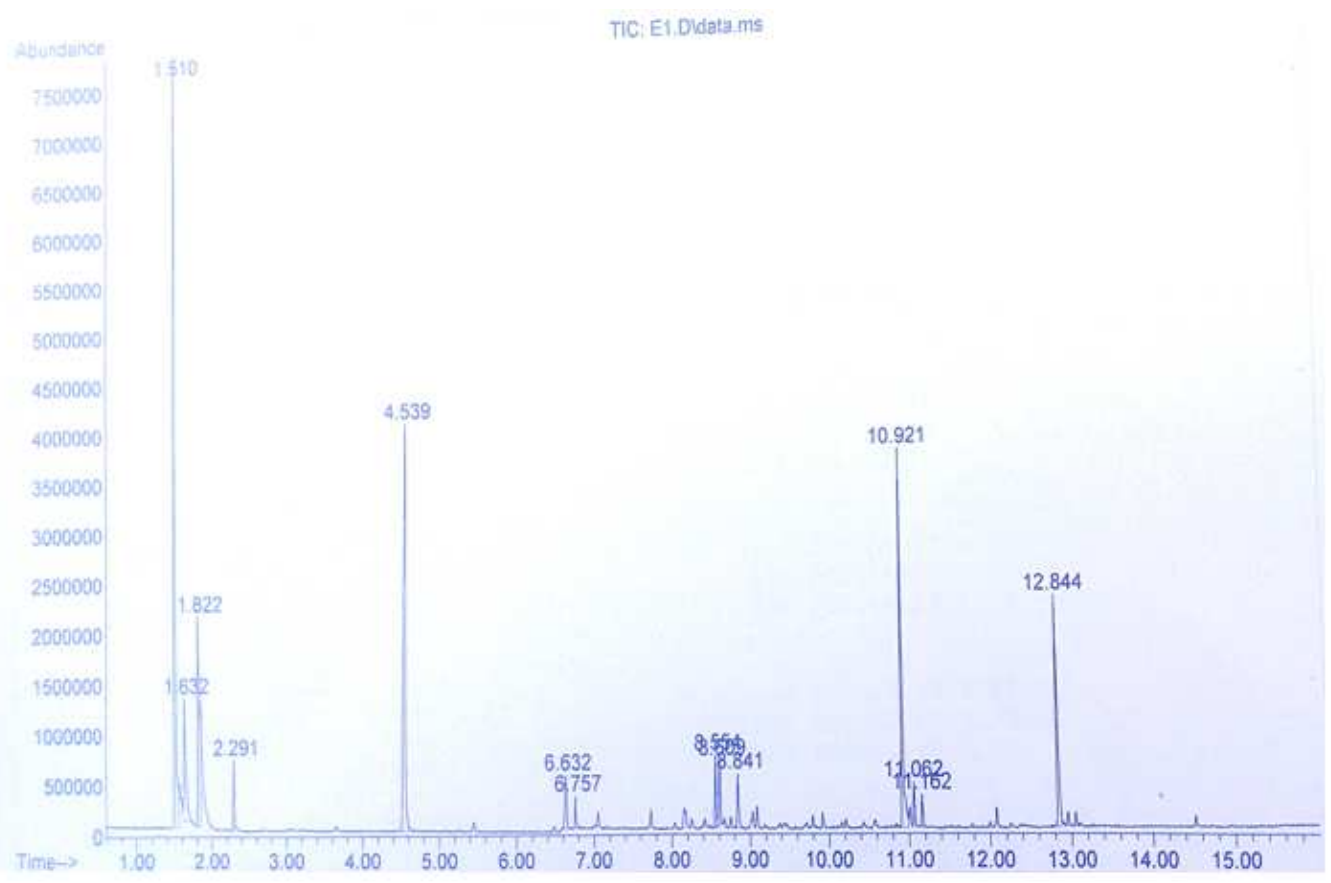

Fig. 5: Chromatogram for sample e, results is presented in Table 5 